\title{
Risk Factors for Obesity among School Aged Children in Kakamega County, Kenya
}

\author{
Micky Oloo Olutende $^{1 *}$, Dr. Maximilla N. Wanzala ${ }^{2}$, Issah Kweyu Wabuyabo ${ }^{1}$, Edwin Kadima Wamukoya ${ }^{3}$ \\ ${ }^{1}$ Department of Health Promotion and Sports Science, Masinde Muliro University of science and Technology, Kakamega Webuye, \\ Kenya \\ ${ }^{2}$ Department of Public Health, Masinde Muliro University of Science and Technology, Kakamega Webuye, Kenya \\ ${ }^{3}$ Professor, Department of Public Health, Masinde Muliro University of Science and Technology, Kakamega Webuye, Kenya
}

DOI: $10.36348 /$ jaspe.2021.v04i04.003 | Received: 08.03.2021 | Accepted: 12.04.2021| Published: 13.04 .2021

*Corresponding author: Micky Oloo Olutende

\section{Abstract}

Obesity is a complex condition that is caused by a mixture of medical, psychological and environmental factors. Childhood obesity is characterized by rise in the number of fat cells. It is one of today's visible yet neglected Public Health problems with serious health implications such as type 2 diabetes, hypertension and cardiovascular diseases that affect individuals in all ages and socio-economic groups. This was a cross-sectional study aimed at investigating the prevalence of obesity and factors that contribute to its occurrence among school-aged children in Kakamega. The objective of the study was to determine prevalence and risk factors among school aged children attending both private and public schools in Kakamega county. Purposive sampling was used to select the target geographical area, simple random sampling was used to identify twenty-four schools, stratified sampling was used to select the class levels (1-4) and systematic sampling was used to select the target population (400 pupils). Data were collected by use of Structured questionnaire and anthropometric data sheet. Statistical package for social sciences (version 25), Epi-info, Nutri-Survey were used to analyze data. Pearson's Product moment correlation and chi-square was used to test the hypotheses. Results from the test indicated that there was a significant relationship between type of school and obesity $(\mathrm{x} 2=49.626, \mathrm{p}<0.05)$, there was no significant relationship between gender and obesity $(x 2=2.867, \mathrm{p}>0.05)$, there was a significant relationship between leisure activity and obesity $(\mathrm{x} 2=4.094, \mathrm{p}<0.05)$ and there was a significant relationship between meals consumed for dinner and obesity $(\mathrm{x} 2=71.123, \mathrm{p}<0.05)$. Pearson product moment correlation results indicated that there was a significant but very weak negative correlation between time spent on physical activity and obesity. $(\mathrm{r}=0.2, \mathrm{p}=0.038)$. Prevalence of obesity among school-aged children was found to be $25.6 \%$ with more boys (27\%) being obese than girls $(26 \%)$. Factors that were associated with the development of obesity were low levels of physical activity and consumption of foods that are dense in carbohydrates and fats. In schools studied 58\% of the pupils ate three times in a day although majority of the respondents from public schools had fewer meals in a day than those in private schools. Respondents from public schools were found to be more active than those in private schools. $40 \%$ of the pupils from public schools spent their time playing while 39\% spent their leisure time watching television. This study concludes that prevalence of obesity among school aged children in Kakamega is quite high which compares to rates in most developed countries. There is need to plan for most efficient interventions not only to ensure that we are food secure but also maintain healthy lifestyles and reduce the prevalence of obesity among school-aged children.

Keywords: Child obesity, Kakamega county, Kenya, risk factors, prevalence, non-communicable diseases, diabetes.

Copyright () 2021 The Author(s): This is an open-access article distributed under the terms of the Creative Commons Attribution 4.0 International License (CC BY-NC 4.0) which permits unrestricted use, distribution, and reproduction in any medium for non-commercial use provided the original author and source are credited.

\section{INTRODUCTION}

Obesity is a condition of abnormal or excessive fat accumulation in the adipose tissue to the extent that health maybe impaired [1]. Obesity results when the number or size of fat cells in a person's body increases. A normal sized person has between 3035 billion fat cells which increase in size and later in number [2]. Childhood obesity is rapidly emerging as a global epidemic (World Health Organization, 2002). Childhood obesity is not only a daily problem for most pediatricians and parents in most economically developed countries but also it is becoming a burden for developing countries as well [3]. The increased burden of childhood obesity in this last year's involves both its prevalence and development at an earlier age with 
increased occurrence of its cormobidities such as diabetes mellitus type2, Cardiovascular diseases and hypertension [4].

Globally it is estimated that 155 million children are obese. The prevalence rate worldwide ranges at $25 \%$, America is $37 \%$, Europe $35 \%$, Middle East $25 \%$, and Asia $15 \%$ and in Africa it is estimated to be $8.4 \%$. Studies conducted among the pre-school children from several African countries indicate that South Africa had a prevalence rate of $31.9 \%$, Algeria 21.6\%, Seychelles 25\%, Malawi $8.4 \%$ and Mauritius $5.6 \%$. Kenya $4.6 \%$. However, there are limited representative data available from African countries for studying the trends on childhood obesity [5]. Prevention is the only feasible option for curbing this epidemic since current treatment practices for obese children and adolescents are largely aimed at bringing the problem under control rather than effecting a cure [6]. Childhood obesity has become an area of public health concern because children are at an increased risk of carbohydrate intolerance, increased insulin, coronary heart diseases, hypertension and orthopedic problems [7]. Obesity is becoming a public health concern in Kenya especially among the urban population. This is attributed to the changes in lifestyle for example individuals have shifted from active to sedentary, changes in dietary habits; foods consumed are mostly carbohydrates and fats which provide more calories than what is expected [8]. According to WHO [9] a modern society is characterized by urban residence with facilitated transport with a decreased levels of physical inactivity poor dietary practices which are some of the risk factors associated with occurrence of obesity. Thus, there is need to provide information on prevalence and factors associated with occurrence of overweight and obesity among children in Kakamega county. The results from this study will contribute a great deal to the study carried out by other researchers in the same field and to policy makers in the entire world more so in countries with a high prevalence of obesity. They will be able to come up with an appropriate nutrition policy which will help mitigate this problem before it reaches epidemic proportions in our country.

\section{METHODS}

A cross-sectional research design was used in the study. In a cross-sectional research design subjects are assessed at a single time. It is less time consuming since it involves testing several groups at the same point in time hence a large number of subjects can be tested at a little cost [10]. It was used to determine the prevalence and risk factors for obesity among school aged children in Kakamega county, Kenya

\section{Subjects/groups}

The study population comprised of children from primary schools both female and male attending private and public schools in Kakamega county. Those children aged between 7-10 years formed the target population. It was chosen because studies conducted globally have indicated that obesity management at a tender age may have greater effect than in adulthood. The class teachers of respective classes were also included in the sample. The inclusion criteria were; Those children whose parents gave consent, those children who were in the age bracket (7-10 years) and those children who have been in that school for more than a year. The exclusion criteria were; Those children who were physically challenged, those children who were sick and those children attending boarding schools. Simple random sampling was used to pick day schools. This method was appropriate since it allows each member of the population to have an equal chance of being included in the sample [11].

\section{Measures \\ Questionnaire}

Data were collected by use of a questionnaire administered to the children. It contained both structured and unstructured questions in order to get indepth responses with clarity to meet the designed objectives for the study. English language was used during the interview though Kiswahili was used where clarity was required. Information sought included: Types of foods consumed by children, dietary patterns, level of physical activity, and factors influencing eating habits.

\section{Observation Checklist}

This instrument gathered information on types of foods consumed by the children in school, types of snacks sold in school, types of activities they performed while in school and presence of field and any playing equipment. This was done during break-time, lunch and during physical activity lessons.

\section{Anthropometric Data Sheet}

The height and weight of children were taken and recorded on the anthropometric data sheet. Each child's height was taken using a height board. The child removed shoes and excessive clothing stood on a flat surface against the wall and the measurement was read. The weight measurements were taken by use of bathroom scale. Where each child removed their shoes and excessive clothing stood on the bathroom scale. The researcher would take the measurements while the research assistant would record. Each measurement was entered twice in order to cater for any errors and ensure accuracy.

\section{Statistical Analysis}

Data analysis was done using Epi-info statistical package, Nutri-survey and statistical packages for social sciences. Nutri- survey statistical package was used to analyze the 24-hour recall results. Epi-info was used to analyze the anthropometric data in order to determine the BMI, which was graded according to [5] age specific cut-off points for children; the children were classified as either normal, underweight, 
Micky Oloo Olutende et al., J Adv Sport Phys Edu, Apr, 2021; 4(4): 59-67

overweight or obese. The BMI values were transferred to SPSS for analysis of the relationship between obesity, which was the dependent variable, and independent variables, which included: children's socio-demographic characteristics, types of foods consumed and level of physical activity. Relationships between the variables were tested using chi-square, Ttest and Pearson's product moment correlation. All relationships were tested at 0.05 level of significance. Descriptive statistics such as mean and percentages were used to describe data in this study. The results obtained after analysis were presented by use of pie charts, tables and bar graphs.

\section{RESULTS}

The total number of respondents was 400 . Weight is one of the anthropometric measures that was taken. It is used to ascertain how heavy an individual is. The highest recorded weight was $90 \mathrm{~kg}$ while the minimum was $18 \mathrm{~kg}$. The mean weight of the total population was $31.7 \mathrm{~kg}$. The results of table 3 below show that $(42.5 \%)$ of the respondents fell in the category of $30-39 \mathrm{~kg}$ while $(39 \%)$ belonged to $50-59 \mathrm{~kg}$ category. the least number of respondents $0.5 \%$ fell in the category of $60-69 \mathrm{~kg}$ and $0.3 \%$ were in the category of $70-79$ and $90 \mathrm{~kg}$ and above respectively as indicated in Table-1 below.
Table-1: Weights of Respondents

\begin{tabular}{|l|l|l|}
\hline Weight Category & Frequency & Percentage \\
\hline $10-19$ & 6 & 1.5 \\
\hline $20-29$ & 58 & 14.5 \\
\hline $30-39$ & 170 & 42.5 \\
\hline $40-49$ & 6 & 1.5 \\
\hline $50-59$ & 156 & 39.0 \\
\hline $60-69$ & 2 & 0.5 \\
\hline $70-79$ & 1 & 0.3 \\
\hline $80-89$ & 0 & 0 \\
\hline Above 90 & 1 & 0.3 \\
\hline TOTAL & $\mathbf{4 0 0}$ & $\mathbf{1 0 0}$ \\
\hline
\end{tabular}

\section{Dietary Practices of the Respondents}

According to Wabitsch [2], food continues to be a major factor in the development of the whole person throughout the growing years. The environment in which the child's lives determine the food behaviour and quality of nutrition. School aged children require three meals and consume snacks twice in a day. Majority of the respondents $(58 \%)$ consumed food three times in a day while $(25.3 \%)$ consumed food two times in a day, $14.8 \%$ ate any time of the day and $2 \%$ ate once in a day as indicated in Table- 2 below. This is in agreement with Bertone [12] who pointed out that majority of westernized societies have adapted having three meals a day however there is an increasing tendency in those industrialized societies for more frequent less well-defined eating occasions.

Table-2: Number of Times Respondents Ate in a Day

\begin{tabular}{|l|l|l|l|l|}
\hline Eating occasions & Male & Female & TOTAL & Percentage \\
\hline Once & $4(2.0 \%)$ & $4(2 \%)$ & 8 & 2.0 \\
\hline Twice & $44(22 \%)$ & $57(28.5 \%)$ & 101 & 25.25 \\
\hline Thrice & $119(59.5 \%)$ & $113(56.5 \%)$ & 232 & 58.0 \\
\hline Anytime & $33(16.5 \%)$ & $26(13 \%)$ & 59 & 14.75 \\
\hline TOTAL & $\mathbf{2 0 0}$ & $\mathbf{2 0 0}$ & $\mathbf{4 0 0}$ & $\mathbf{1 0 0 . 0}$ \\
\hline
\end{tabular}

\section{Recommended Daily Allowance}

Proteins build tissues, produce fluids and repair tissues while carbohydrates aide in growth and production of energy which is required for the chemical processes i.e., breathing, digesting food, excrete waste, keeping body warm, secrete fluids and pumping of blood; sources include: starches, sugars and fat while energy is generally measured in kilocalories. Vitamins and minerals protect the body from diseases and infections. Results from Table-3 below shows that the frequency of consumption of foods from the four food sources was good. The frequency levels were as follows: (81\%) for cereals, (64\%) vegetables, (75\%), fruits $(83.7 \%)$ for pulses. This is a clear indication that most parents are employed therefore are in a position to purchase food for their family members. The frequency of animal product and tuber consumption was low (23\% and $9.5 \%$ ) respectively. This can be attributed to the cost of animal product which are normally expensive and not all the individuals can afford on a daily basis especially individuals low socio-economic groups. Tubers such as arrowroots yams and cassavas are not common foods as compared to other food sources that are easily available in all the regions countrywide.

Table-3: Frequency of Consumption of Foods by School Aged Children

\begin{tabular}{|l|l|l|l|}
\hline Food types & Frequency & Frequency of consumed daily & food \\
\hline & N $\%$ & & \\
\hline Cereals & 32481 & Frequent & \\
\hline & 7619 & Not frequent & \\
\hline Vegetables & 25664 & Frequent & \\
\hline & 14436 & Not frequent & \\
\hline Fruits & 30275.5 & Frequent & \\
\hline
\end{tabular}


Micky Oloo Olutende et al., J Adv Sport Phys Edu, Apr, 2021; 4(4): 59-67

\begin{tabular}{|l|l|l|l|}
\hline Food types & Frequency & Frequency of consumed daily & food \\
\hline & 9824.5 & Not frequent & \\
\hline Pulses & 33583.7 & Frequent & \\
\hline & 6516.3 & Not Frequent & \\
\hline Animal products & 9223 & Frequent & \\
\hline & 30877 & Not frequent & \\
\hline Tubers & 389.5 & Frequent & \\
\hline & 36290.5 & Not frequent & \\
\hline
\end{tabular}

\section{Level of physical activity of respondents}

The most favorite sport was football $(32.8 \%)$

Running as sport came second (9.5\%) balling (7.5) volleyball (4.5\%) and table tennis (2.3\%). In a day the children would play more than one sport and learn more about the sport as they grow. According to Murray [13], it is important to nurture skills in organized sports especially at tender age as they are easily mastered at a younger age than in adulthood. He further reckons that sport should not be gender specific. Figure-1 below indicates the number of times the pupils had physical activity in a week. A majority $(42.5 \%)$ attended physical exercise lessons once a week slightly above a third $(35 \%)$ stated twice, while the most times physical exercise were mentioned by only $(15.0 \%)$ of the respondents. Lastly $(7.5 \%)$ stated that they attended the physical exercise lessons three times. Private schools had fewer reports on attendance of physical exercise lessons. This was because the students had many extracurricular activities incorporated in their school programme thus time slotted for physical activity was less. While in other schools they had to hire grounds thus limiting the number of times the children attended the lessons. The pupils were asked to state their means of transport to school as shown in Figure 4.3 below. Most pupils used school transport (30.3\%), followed by those who walked to school $(29.5 \%)$ and those who used public transport were $(23.7 \%)$ while $(16.5 \%)$ used private means to school. A cross tabulation between school type and mode of transport indicates that majority of children (55\%) from public schools walked to school while those attending private schools were only (3\%) who walked to school. Majorities $(96.1 \%)$ of children attending private schools used either school bus or were dropped to school by their parents. Most of the pupils in public schools came from poor socioeconomic backgrounds. Thus, they could not afford to pay school transport or public transport. They had to succumb to the long distances and harsh weather conditions to school. The main reasons given for preference to be dropped to school were: increases in the level of insecurity, harsh weather conditions, enjoy the ride to school, to avoid being tired by the time they arrive in school and distance between school and home was quite long. Reasons given for preference to walk to school: To be physically fit, distance between home and schools were short and enjoyed each others company as they walked to school. Most of the children who watched television were taken to school by bus (38.5\%) or dropped by parents to school (36.1\%). Only $25 \%$ walked to school while those who engaged in household chores mainly walked to school (44\%) While those who played a majority were taken by bus $(39 \%)$ or walked (36\%). There was a significant relationship between means of transport and type of leisure activity. $\left(\mathrm{x}^{2}=\right.$ $18.690 ; \mathrm{df}=6 ; \mathrm{p}<0.002$ )

Majority of the pupils (34\%) spent their time watching television, while $(27 \%)$ played, playing computer games was represented by $(22.2 \%)$ and only $(16 \%)$ assisted in household chores. Majority of children from public schools spent their leisure time assisting in household chores (76.1\%) and playing $(67.8 \%)$. While children from private school's majority spent their time watching television $(83 \%)$ and playing computer games (86.2\%). Most of the children attending private schools came from affluent families, who can afford to employ a house help; who does all the household chores while they sit and watch television or playing computer games while snacking this predisposes them to gradual increment of body weight and eventually develop obesity or overweight due to consumption of empty calories. There was a significant relationship between leisure activity and school type $\left(\mathrm{x}^{2}\right.$ $=90.178 ; \mathrm{df}=3 ; \mathrm{p}<0.001)$. Males dominated computer games $(52.3 \%)$, watching television $(54.9 \%)$ and playing $(57 \%)$. Household chores were mainly undertaken by females (68.5\%). In the African culture girls are trained and brought up knowing their roles as home makers while boys are taught to learn their responsibility as providers. There was a significant relationship between how leisure was spent and gender of the school aged children. $\left(x^{2}=16.263 ; \mathrm{df}=3 ; \mathrm{p}<\right.$ $0.001)$. This was further supported by the significant relationships that occurred between various leisure activities and type of snacks consumed. 
Prevalence of overweight and obesity

Table-4: Age Specific Cut-off Points for Overweight and Obesity

\begin{tabular}{|l|l|l|l|l|}
\hline $\begin{array}{l}\text { AGE (in } \\
\text { years) }\end{array}$ & $\begin{array}{l}\text { BMI cut of points for BMI cut off points for obese } \\
\text { overweight }\end{array}$ \\
\hline & Boys & Girls & Boys & Girls \\
\hline 5 & 17.2 & 17.15 & 19.30 & 19.17 \\
\hline 6 & 17.55 & 17.34 & 19.78 & 19.65 \\
\hline 7 & 19.92 & 17.75 & 20.63 & 20.51 \\
\hline 8 & 18.44 & 18.35 & 21.60 & 21.57 \\
\hline 9 & 19.10 & 19.07 & 22.77 & 22.81 \\
\hline 10 & 19.84 & 19.86 & 24.00 & 24.11 \\
\hline
\end{tabular}

Source: IOTF (2002) [5] recommended cut-off points for overweight and obesity

BMI it is the accepted standard of measure for overweight and obesity among children it has a strong association with body fatness and health risks [14]. It was calculated using the Epi-info computer package. The results were then categorized according to the accepted age specific cut-off points for children [5] as indicated in Table-4 above. In all categories of weight status there was almost an equal distribution of both male and female as indicated in table 4.3 below (27\%) of the boys were obese while $(26 \%)$ of the girls were obese. However, there were more girls $(27 \%)$ who were overweight than boys $(20 \%)$ as indicated in Table-5 below. A study conducted by [8] among pre-adolescent in private schools in one division in Nairobi Province Kenya indicated that the prevalence was $38.1 \%$ with more girls being obese than boys. (Sample of 120 was used). The results concur well with [5] results that indicate obesity is rising significantly in developing nations more so among the urban populations. This finding differs with IOTF study in Africa, America, Europe, and Asia indicated that the prevalence rate of overweight and obesity were the same. However, in this study boys were found to be more obese than girls especially those who were aged between 9-10 years though girls were more overweight than boys. This can be attributed to their eating habits as majority of the children consumed snacks that were dense in fats and carbohydrates and exhibited lesser levels of physical activity.

Table-5: Gender and Weight Status of School aged Children

\begin{tabular}{|c|c|c|c|c|c|c|c|c|}
\hline SEX & \multicolumn{6}{|c|}{ BODY MASS INDEX } & \multirow{2}{*}{\multicolumn{2}{|c|}{ TOTAL }} \\
\hline & \multicolumn{2}{|c|}{ obese } & \multicolumn{2}{|c|}{ overweight } & \multicolumn{2}{|c|}{ normal/underweight } & & \\
\hline & count & percent & count & percent & count & percent & count & percent \\
\hline Boy & 54 & 27 & 40 & 20 & 106 & 53 & 200 & 100 \\
\hline Girl & 52 & 26 & 54 & 27 & 94 & 47 & 200 & 100 \\
\hline Total & 106 & 26.5 & 94 & 23.5 & 200 & 50 & 400 & 100 \\
\hline
\end{tabular}

\section{Relationship between leisure activity and obesity}

There was a significant relationship between leisure activity and obesity $\left(\mathrm{x}^{2}=4.094\right.$, df $=6$, $\mathrm{p}<0.001)$. The findings of this study are similar to what [15] sited adoption of a sedentary type of lifestyle as among the major contributes that has led to the rise in the levels of obesity. It was observed that (42\%) of children who spent their time watching television were obese and $(37 \%)$ who played video games were also obese. The children who participated in household chores were normal or underweight. There was also a significant relationship between leisure time and school type $\left(\mathrm{x}^{2}=90.178\right.$, df $\left.=3, \mathrm{p}<0.001\right)$. Among children who played computer games $(86.2 \%)$ and $(83 \%)$ watched television attended private schools. Most children who attended public schools (76.1\%) participated in household chores and (67.8\%) spent their free time playing.

\section{Relationship between mode of transport and obesity}

A chi-square indicated that there was a significant relationship between mode of transport and obesity $\left(x^{2}=14.689, \mathrm{df}=, 3, \mathrm{p}<0.002\right)$. Majority of the children used either school bus or were dropped by their parents to school; a minority preferred to walk to school. It predisposes the children further to weight gain for those who were using either the school bus or parents' car. In addition, there was a significant relationship between leisure activity and mode of transport $\left(\mathrm{x}^{2}=18.690, \mathrm{df}=6, \mathrm{p}<0.003\right)$. Most of those children who watched television or played computer games most of their free time were either using school bus or being dropped by their parent to school they were overweight or obese; while those who spent their free time engaged in household chores, mainly walked to school fell in the category of normal and underweight.

\section{Relationship between physical activity and obesity \\ Pearson's product moment correlation was used. It shows that there was a significant but weak correlation between time spent on physical activity and obesity $(r=-0.012, p<0.048)$ Obesity levels decreased}


with the increase in the amount of time spent on physical activity.

\section{Relationship between food consumption patterns and obesity}

Nutrition is essential to health and quality of life at every age. A normal healthy child grows at a genetically pre-determined rate that can be compromised or accelerated by nutrition imbalance, over nutrition or under nutrition. The results of this study indicate that there was a significant relationship between dietary practices and obesity. There was a significant relationship between weight status and meal consumed for dinner $\left(\mathrm{x}^{2}=71.123\right.$, df $\left.=6, \mathrm{p}<0.001\right)$. Majority of the children (46\%) who were obese took a balanced dinner; (38\%) consumed meals for dinner that were high in calories, while those who were overweight (44\%) consumed meals for dinner that were not balanced and (38\%) and those who were in the underweight and normal category majority consumed balanced meals for dinner. There was a further significant relationship between weight status and meals consumed at break time $\left(\mathrm{x}^{2}=62.82\right.$, df $\left.=4, \mathrm{p}<0.001\right)$. The children who were obese $(85 \%)$ consumed foods that had a high caloric content; $(51 \%)$ of those who were overweight also consumed foods that were dense in calories; while those who were normal or underweight majority did not carry or consume any food at break time. It indicated that majority of the obese children $(85.7 \%)$ consumed foods that were dense in calories and (51.0\%) who were overweight also carried meals that were dense in calories. (47.3\%) who fell in the category of underweight and normal, majority did not carry meals for break-time. There was a significant relationship between obesity and consumption of chocolates, baked items and fried items $\left(x^{2}=25.280 ; \mathrm{df}=2, \mathrm{p}=0.001, \mathrm{x}^{2}=52.603 ; \mathrm{df}=2, \mathrm{p}=\right.$ 0.001 and $x^{2}=64.839$, df $=2 ; p=0.001$ ) respectively. There was a significant relationship between meals consumed for breakfast and weight status $\left(x^{2}=60.286\right.$, $\mathrm{df}=6, \mathrm{p}<0.001) .(34 \%)$ of the children who were obese consumed breakfast meal that was high in caloric content; (61\%) of the children who were obese consumed breakfast meal that were dense in calories and $(69.7 \%)$ of the children who fell in the category of normal/underweight consumed meals for breakfast that was not balanced however, (15\%) of them took breakfast that were dense in caloric content. Pearson correlation results indicated a positive correlation between number of meals consumed and obesity ( $\mathrm{r}=0.5$, $\mathrm{p}<0.038$ ) Obesity levels were high with the increase in the number of meals consumed. There was a further positive correlation between amount of carbohydrates consumed and obesity $(\mathrm{r}=0.4, \mathrm{p}<0.003)$. Obesity levels increased with an increase in the amount of carbohydrates consumed.

\section{Relationship between gender and obesity}

There was no significant relationship between gender and obesity $\left(\mathrm{x}^{2}=2.687, \mathrm{df}=2, \mathrm{p}>0.260\right)$. Thus, alternative hypothesis was rejected.

\section{Relationship between Socio- Economic Status and} Obesity

T-test was used to test the relationship between socio-economic variable and obesity. There is a relationship between socio-economic status and obesity $(\mathrm{p}<0.003)$. This is indicated by number of pupils who obese majority were being from private schools. This was also clearly indicated by their dietary habits and levels of physical activity. They consumed foods that were dense in empty calories and fats and engaged. Less in physical activity therefore easily succumbed to development of obesity. The findings of this study are not in agreement with [16], who states that in industrialized countries the prevalence of obesity is higher in individuals in low socio-economic groups. This is in contrast with the situation in developing countries where the lesser obese rates are observed in low SES populations. However, further studies have indicated that high SES is positively correlated with obesity in developing countries. The higher the economic status the more money one has available to spend hence over eating of foods rich in fats and carbohydrates. Chi-square test indicated a significant relationship between obesity and school type $\left(\mathrm{x}^{2}=49.626, \mathrm{df}=2, \mathrm{p}<0.001\right)$. Majority of the children who were obese came from private schools $(41 \%)$ and $12 \%$ were from public schools. Children who attended public schools a significant number came from lowincome class

\section{DISCUSSION}

The general objective of the study was to determine prevalence and risk factors among school aged children attending both private and public schools. Findings revealed that children gain more weight than height; body proportions begin to change as they get ready for the final growth spurt during adolescence, respondents in this study fell in the age category of seven and ten years. These shows that the children are still in the stage of growth and development. They require nutrients from all the five groups of food sources. However, they require more energy sources to aide not only their growth and development but also to replace the energy lost during physical activity. In most of private schools they did a commendable thing by offering a variety of foods from which the children could choose. $80 \%$ of the meals offered in schools were balanced however; certain foods offered were high in fats for example chips and sausages, burgers and pizzas such meals should be discouraged from schools. In public schools they did not have a range of food choices being offered at lunch hour. It mainly consisted of carbohydrate and protein nutrients though majority of the children took their lunch at home and a few bought from food vendors who came at lunch hour. It is estimated that each additional can or glass of sugarssweetened drink that they consume everyday increases the risk of being obese by $60 \%$ [17]. Consumption of too much calories increases the chances of having excess body weight. Carbohydrates are the only fuel 
Micky Oloo Olutende et al., J Adv Sport Phys Edu, Apr, 2021; 4(4): 59-67

source for many vital organs. Digestive system breaks down carbohydrates and aides in its absorption in bloodstream through to the body cells.

Consumption of low carbohydrate diet does not help in losing weight instead it deprives the body essential nutrients. It is more difficult to become obese by eating a very high carbohydrate diet than eating a very high fat diet. There are effective feedback and control mechanisms for regulating and balancing carbohydrate intake and oxidation. Whatever diet an individual chooses to adapt carbohydrates should not be eliminated it is required to metabolize fat. Individuals should choose carbohydrates that are unrefined or unprocessed i.e. whole grains, cereals, fruits and vegetables [18]. Proteins choose once that are low in saturated fat i.e., lean cuts of red meat, fish, lean chicken and pork or plant sources e.g., Soya and its products, legumes and tissue found on skin surface. It was found that women who have lowered fat intake have reduced body weight providing further evidence of a positive association between fat intake and body weight [19]. Protein consumed in excess of what is needed is converted to carbohydrate.

Let children adapt to a regular eating pattern and avoid random eating as this makes them to consume large amounts of junk foods and soft drinks that are dense in sugars and fat. In many countries worldwide individuals are used to taking three meals in a day. There is an increasing habit emerging mainly in industrialized societies for more frequent and less welldefined eating occasions in both adults and young people with increased snack consumption at more frequent or irregular intervals [20]. Children who were aged between nine and ten years most of them said that they ate frequently and it included both the snacks and meals. For example, at 4p.m on their way home they would take a snack and on arriving home they would take a meal and during dinner they would also take whatever meal that was served. This is an indication of very poor dietary practices. $47 \%$ of the children in both public and private schools consumed meals for dinner that was balanced but higher proportion were from the private schools. While majority from private schools took dinner that was high in calories and majority from public schools took meals that were not balanced. Dinner is the main meal of the day and should not be skipped. It gives an opportunity to share and talk about activities and events of the day. However, children at this age are very choosy thus parents should ensure that they not only provide a variety of meals but also prepare and serve in an attractive manner to heighten their appetite. In most cases children may refuse to take the meals thus ensure that the afternoon meal is nutritious. $76 \%$ of the children in public schools consumed breakfast that was not balanced and $11 \%$ did not take breakfast while those in private schools $41 \%$ took a breakfast meal that was not balanced. $28 \%$ took breakfast meal that was balanced and $22 \%$ took one that was dense in energy.

Breakfast is a very important meal, which should not be skipped since it is the first meal of the day. Studies have shown that eating breakfast maybe associated with decreased snacking and fat intake later in the day [21]. There was a significant relationship between meals consumed for dinner, breakfast and school type. Breakfast is very important meal should not be skipped. It helps a child to stay active and concentrate at school. Thus, parents should ensure that this first meal of the day is balanced. Several factors influence children's food choice: High availability of a variety of foods this is indicated by the increased vending machines and canteens in schools, fast foods are located everywhere providing a variety of food choices at low prices. Routine: children and adults who eat regular meals tent to have better diets than those who eat randomly. Marketing: there is an increased advertisement and marketing of snacks and other foods and also eating-places mainly put in an attractive manner to capture people's attention thus luring them to purchase. Emotions: Depression, anxiety, boredom and stress often lead to unhealthy eating habits in which an individual can resort to anorexia nervosa or bulimia. Knowledge of nutrition: Most children are not enlightened on matters regarding nutrition and their health [22].

The children made an independent decision on what snacks they would carry to school with (72\%) and $28 \%$ of the children from private and public schools respectively. This is a clear indication of negligence among parents. They live their children to learn and make wrong food choices, which later will impact on their health. Sixty percent of the children never participated in meal preparation while thirty percent occasionally participated in meal preparation and only $10 \%$ participated in meal preparation. Most of the parents are not being good role models to their children. Repeated exposure to certain foods influences a child's preference for that food. Thus, if parents like buying ice-creams chances are high that a child will make the same choice. According to a Cornell University study indicates that children who ate sweets most likely parents to like consuming sweets. A young child's preference for snacks is related to what parents do or do not allow. There is a marked improvement in standards of living; both parents are working thus most of the roles for the woman is delegated to the house helps whom in most cases might not be relating well with the children. The food choices made in most cases may not meet the nutritional standards. Despite mothers having a busy schedule they should try and at least have time for their children: plan and prepare meals together go for shopping together with their children let them make choices of food with guidance, eliminate unhealthy foods from the house and avoid preparing high fat convenience foods. This will not only enable them to 
attain knowledge but also skills. This enables them to grow up into responsible individuals who value a healthy lifestyle.

Energy expenditure like energy intake is an important factor in the development or protection against obesity. Physical activity not only uses up stored energy but also helps to stimulate muscle development. The more muscles one has the more kilojoules you can burn. Children in both the public and private schools had physical education lessons at least once in a week (period of 35 minutes). However in public schools the frequency in attendance was quite higher compared to that in private schools most of them attended at least three times in a week. $98.3 \%$ of the children had a positive attitude towards physical activity major reason being enjoyment of the activities they indulged in during the lessons while others it gave a break to that monotony of being in class for long hours. $38.2 \%$ of the respondents used school bus to school $33.3 \%$ were dropped by their parents and $28.5 \%$ walked to school. This high rate of motorized means of transport was attributed to several factors which include: increased cases of insecurity distance between school and home is quite long and most children did not want to get tired while walking to school. $80 \%$ of the children given an option preferred to be dropped than walking to school main reason; they did not want to get tired while walking to school. This is a clear indication of poor attitude or lack of motivation and emphasis of always being physically fit. Parents and teachers have the duty to encourage and help their children develop a positive attitude towards engaging in physical exercises; for example: They as guardians should be role models by exercising regularly, watch their child/children as they play sports, involve them in a joint family outing where everybody participates in physical activity and assist them nature their favorite or identified sport talent in them if possible take them to professional matches so that they can get inspired by watching their sporting heroes in action.

Majority of the children from public schools walked to school mainly because they could not afford to pay for school bus or normal means of transport, they had no option but to brave the weather conditions and insecurity cases and walk to school. Children should be taught both at home and in school the benefits of being physically fit. $31 \%$ of the children spend their leisure time watching television and playing (30\%). Majority were boys while girls spent their time carrying out household tasks. This can be associated to the proportion of girls who were obese being low. There was a significant association between those who watched television; played computer games and those who were obese. There was also a significant relationship between leisure and consumption of snacks for example fried items. Results from this study indicate that children who spent their time playing computer or video games and watching television highly consumed snacks. This was shown by the frequency in which they took the snacks which was rated as thrice or frequently. However, children whom were actively involved in household chores consumed snacks less. Multivariate studies have found that television viewing and playing video games for longer periods of time or not participating in sports outside of school promotes obesity [23]. The links between television viewing and weight gain may also be affected by other social factors for example the use of television as a child care substitute [24]. The children complained on lack of field where they could play comfortably while others did not just like to interact with other children in the neighborhood this was a common response from the female respondents.

While others were restricted by their parents not to leave the house so they just resorted to watching television or played computer games. When children concentrate in television for long hours, they not only get to learn of food stores but also, they learn of the new products in the market. In most cases heavy marketing of energy dense foods often targets children who are unable to distinguish between programme content and persuasive intent of advertisements. Parents should discourage eating and watching television as this increases chances of taking more calories than what the body requires. Furthermore, they should restrict time spent on sedentary activities and involve them in physical activity in the house e.g., cleaning windows, gardening, cleaning the car and tidying up their room. This particular stage in a child's life provides a perfect time for children to learn about healthy foods as they start a busy social life, being responsible and accountable for their actions and begin to choose their own lifestyle. They learn quickly therefore good habits are best nurtured at this level.

\section{CONCLUSIONS}

On the basis of the outlined findings the following conclusions were drawn: The incidence of childhood obesity has gone high which predisposes the child to certain chronic such as type 2 diabetes whose incidence among children is going up. Therefore, as the prevalence of obesity increases and so does the prevalence of comorbidities associate with obesity. The prevalence of obesity was significantly high among the low-income class. Boys are at high risk of being obese and overweight compared to the girls. The more the amount of time spent on exercises the lower were obesity levels. The more the meals consumed in a day the higher the levels of obesity and the more the amount of carbohydrates and fats consumed the higher the levels of obesity.

\section{ACKNOWLEDGMENTS}

We would like to express our gratitude to athletes for their co-operation. And not to forget the extraordinary efforts of the field staff. 


\section{ETHICAL DISCLOSURES}

\section{Protection of human and animal subjects}

The authors declare that the procedures followed were in accordance with the regulations of the relevant research ethics committee and with those of the Code of Ethics of the Declaration of Helsinki.

\section{Confidentiality of data}

The authors declare that they have followed the protocols of the university on the publication of the data.

\section{Right to privacy and informed consent}

The authors have obtained the written informed consent of the patients or subjects mentioned in the article. The corresponding author is in possession of this document.

Competing Interest: The authors declare that they have no competing interests.

\section{Authors \& Contributions}

Micky Olutende Oloo and Dr. Maximilla Wanzala conceived the paper, designed and performed the study. Issah Kweyu contributed the data collection, integrity, and analysis. Prof Edwin Wamukoya conceived the paper and was the paper's peer reviewer. All authors read and approved the final manuscript.

Funding: No financial support was provided.

Disclaimer: The findings and conclusions presented in this manuscript are those of the authors and do not necessarily reflect the official position of Masinde Muliro University of Science and Technology

\section{REFERENCE}

1. World Health Organization (WHO). (1997). Preventing and managing the global epidemic. Report of a WHO Consultation. Technical reports series no. 894. WHO; Geneva.

2. Wabitch, M. (2002). Molecular and biological factors with emphasis on adipose tissue development. Child and adolescent obesity. Causes and consequences; prevention and Management. Cambridge University Press, pp 50-68.

3. Wang, Y. Montein, G., \& Popkin, B. M. (2000). Trends of obesity and underweight in older children and adolescents. American journal of clinical Nutrition: 75:971-977.

4. Bauer, B., \& Maffeis, C. (2000). Child and adolescent obesity cause and consequences; prevention and management Cambridge University Press: Camdreidge, UK, pp: 361-376.

5. International Obesity Task Force Data. (2002). Based on population weight estimates from published and unpublished survey, (1990-2002), London. pp 14-17.

6. Cole, T. J., Paul, A. A., \& Whitehead, R. G. (2002). Weight reference charts for British Longterm Breastfeeding infants. Paediatric; 91: 1296-1300.
7. Strauss, R. S., \& Pollack, H. A. (2001). Epidemic increase in childhood overweight 1986-1998. JAMA; 286:2845-2848.

8. Malla, J. (2004). Obesity and factors that contribute to obesity among Pre-adolescecnt attending day private primary schools in Nairobi. Master's thesis, Kenyatta University.

9. World Health Organization (WHO). (2003). Diet nutrition and managing the global epidemic: WHO technical report series no.916: Geneva.

10. Thomas J.R, Helson J.K. and Silverman S.J. (2005). Research methods in physical Activity. (5th Ed) Champain in: Human Kinetics. pp 220-230.

11. Mugenda, O. M., \& Mugenda, A. G. (1999). Research Methods. Quantitative and Qualitative approaches, ACT press Nairobi Kenya.

12. Bertone E.R, Staneck E.s, \& Cohen N.L. (2003). Association between eating patterns and obesity in a free-living US adult population. American Journal of Epidemiology, 158:85-92.

13. Murray, C. B., Kagan, C. R., \& Bawendi, M. G. (1995). Self-organization of CdSe nanocrystallites into three-dimensional quantum dot superlattices. Science, 270(5240), 1335-1338.

14. World Health Organization (WHO). (2000). Obesity: Preventing and managing the global epidemic, Report of WHO Consultation Technical Report Series No. 894. WHO; Geneva.

15. World Health Organization (WHO). (2004). International Journal of Public Health: vol: 82 no.12: December pp, 940-946.

16. Latham, M. C. (1997). Human Nutrition in developing world. Food Agriculture Organization; Italy pp 688-700.

17. Wilson, J. F. (2000). Lunch eating behavior of preschool children: effects of age, gender and type of beverage served. Physiological Behavoir; 70:27-33.

18. Lissener, J., Levistly, O., \& Stropp, B. I. (1998). Dietary fat and regulation of energy intake in human subjects. American Journal of Nutrition, 46: 886-892.

19. Salvatoni, A. (2002). Surgical treatment in childhood and adolescent obesity, Cambridge University Press, pp, 355-360.

20. Jahhns, L, Siega-Riz, A. M., \& Popkin, B. M. (2001). The increasing prevalence of snacking among US children. Journal of Pediatrics, 138:493-498.

21. Wolfe, F., Ross, K., Anderson, J., Russell, I. J., \& Hebert, L. (1995). The prevalence and characteristics of fibromyalgia in the general population. Arthritis \& Rheumatism: Official Journal of the American College of Rheumatology, 38(1), 19-28.

22. Westonnoefer, J. (2001). Establishing good dietary habits in capturing the minds of children, Public Health Nutrition; 4:125-129.

23. O'Loughlin, E. V., \& Robins-Browne, R. M. (2001). Effect of Shiga toxin and Shiga-like toxins on eukaryotic cells. Microbes and infection, 3(6), 493507.

24. Shannon, R. V., Zeng, F. G., Kamath, V., Wygonski, J., \& Ekelid, M. (1995). Speech recognition with primarily temporal cues. Science, 270(5234), 303304. 